\title{
EDUCAÇÃO EM E PARA OS DIREITOS HUMANOS: A ESCOLA E O DIREITO A AFIRMAÇÃO DA DIFERENÇA
}

\author{
EDUCACIÓN EN Y PARA LOS DERECHOS HUMANOS: LA ESCUELA Y \\ EL DERECHO A AFIRMAR LA DIFERENCIA
}

\section{EDUCATION IN AND FOR HUMAN RIGHTS: THE SCHOOL AND THE RIGHT TO AFFIRM THE DIFFERENCE}

Tarcia Regina SILVA ${ }^{1}$

\begin{abstract}
RESUMO: As práticas pedagógicas na Educação Infantil constituem-se no temaproblema deste artigo, cujo objetivo é analisar como a questão da diferença tem sido tratada nas escolas da Educação Infantil da microrregião de Garanhuns. Esta pesquisa se ancora na perspectiva da criança como sujeito singular. Baseia-se no pressuposto de que uma Educação pautada em/para os Direitos Humanos, que incorpora desde a Educação Infantil, o direito à diferença na perspectiva da interculturalidade, tem contribuído para que as crianças possam conviver e celebrar as diferenças. Para tal, recorremos aos pressupostos da pesquisa qualitativa de cunho etnográfico para observar as práticas pedagógicas de oito escolas municipais de Educação Infantil em oito municípios da microrregião de Garanhuns-PE relacionados às questões da diversidade religiosa, de gênero, étnico-racial e da educação inclusiva. Os dados coletados evidenciam que ao negar o espaço de convívio com as diferenças as práticas têm reproduzido desigualdades no espaço escolar desde a Educação Infantil.
\end{abstract}

PALAVRAS-CHAVE: Educação infantil. Educação em direitos humanos. Diferença. Desigualdade.

RESUMEN: Las prácticas pedagógicas en la educación infantil se constituyen en el tema-problema de este artículo, cuyo objetivo es analizar cómo la cuestión de la diferencia ha sido tratada en las escuelas de Educación Infantil de la microrregión de Garanhuns. Esta investigación se ancla en la perspectiva del niño como sujeto singular. Se basa en el supuesto de que una Educación pautada en / para los Derechos Humanos, que incorpora desde la Educación Infantil, el derecho a la diferencia en la perspectiva de la interculturalidad, ha contribuido a que los niños puedan convivir y celebrar las diferencias. Para ello, recurrimos a los presupuestos de la investigación cualitativa de cuño etnográfico para observar las prácticas pedagógicas de ocho escuelas municipales de Educación Infantil en ocho municipios de la microrregión de Garanhuns-PE relacionados a las cuestiones de la diversidad religiosa, de género, étnico-racial y de la educación inclusiva. Los datos recogidos evidencian que al negar el espacio de convivencia con las diferencias las prácticas han reproducido desigualdades en el espacio escolar desde la Educación Infantil.

1 Universidade Estadual de Pernambuco (UEP), Garanhus - PE - Brasil. Professora Adjunta. Coordenadora da área de gestão de processos educacionais do PIBID/campus Garanhuns. E-mail: tarcia.silva@upe.br. 
PALABRAS CLAVE: Educación infantil. Educación en derechos humanos. Diferencia. Desigualdad.

ABSTRACT: The pedagogical practices in Early Childhood Education constitute the problem theme of this article, whose objective is to analyze how the issue of difference has been treated in the schools of Early Childhood Education of the micro-region of Garanhuns. This research is anchored in the perspective of the child as a singular subject. It is based on the assumption that an Education based on / for Human Rights, which incorporates since Early Childhood Education, the right to difference in the perspective of interculturality, has contributed to the children being able to live and celebrate the differences. To that end, we have used the assumptions of qualitative ethnographic research to observe the pedagogical practices of eight municipal schools of Early Childhood Education in eight municipalities in the Garanhuns-PE microregion related to issues of religious, gender, ethnic and racial diversity and inclusive education. The collected data show that in denying the space of conviviality with the differences, practices have reproduced inequalities in the school space since Early Childhood Education.

KEYWORDS: Early childhood education. Education in human rights. Difference. Inequality.

\section{Introdução}

Os Direitos Humanos, que inicialmente foram influenciados pelo Iluminismo e pela questão da igualdade, se assumindo dentro de um discurso universal, chegam à contemporaneidade em uma nova configuração que sugere revisitar a cultura escolar à luz de questões advindas do debate acerca da diversidade e da diferença. Assim, a Educação em/para os Direitos Humanos solicita a revisitação das nossas práticas pedagógicas, as quais historicamente tiveram seu alicerce fundado a partir dos argumentos universalistas. Ela reivindica uma educação alicerçada na diversidade e na diferença que nos faça repensar a nós mesmos, nossas práticas, o currículo e a formação dos professores.

Nessa perspectiva, teremos que trazer à tona a centralidade da cultura, pensando nas práticas pedagógicas como um trabalho que, além de competência técnica, exige sensibilidade, diálogo e engajamento social. Exige que repensemos o nosso discurso colonizado, homogeneizado, excludente e etnocêntrico. Em consonância com esta acepção, de acordo com o Plano Nacional de Educação - PNE (BRASIL, 2014), a diversidade precisa ser entendida não apenas como o somatório das diferenças, mas 
como uma construção resultante de um contexto histórico, social, cultural e político das diferenças nos contextos e relações de poder.

Entretanto, cabe-nos diferenciarmos diversidade de diferença e justificar porque, ao longo do texto, utilizamos preferencialmente o termo diferença. De acordo com Moruzzi e Abramowicz (2015), a diversidade propõe a inclusão de alguns repertórios culturais na cena da cultura dominante, enquanto a diferença se propõe a questionar quais desses repertórios podem entrar em cena. Tendo em vista esse panorama, assentimos que a produção das diferenças ultrapassa as características biológicas. Elas são construídas pelos sujeitos ao longo do processo cultural e histórico. $\mathrm{Na}$ contemporaneidade, as lutas pelo respeito a essas diferenças têm sido constantes nos diversos âmbitos sociais. Nesse contexto, assume grande força o debate em torno das identidades que, em termos políticos, resulta do reconhecimento de que certos grupos sociais têm, há muito tempo, sido alvos de inaceitáveis discriminações. A diferença tem sido associada, sobretudo, às relações de poder e autoridade que geram desigualdades (SILVA, 2000).

A partir dessa premissa, manifestamos que a diferença não deve ser compreendida como um processo que contradiz a universalidade, mas como um repensar que ressignifica os Direitos Humanos frente às atuais demandas sociais. Seu caráter universal refere-se ao fato de que todos os humanos têm direito à dignidade, à humanidade e ao pleno exercício da liberdade e da democracia. Entretanto, é preciso considerar que "sua validade está vinculada ao contexto cultural a partir do qual são construídos e reivindicados, a partir do lugar de fala, da identidade e dos pertencimentos dos sujeitos que os reivindicam" (SILVA, 2012, p. 14). O debate conflituoso entre proposições relativistas e universalistas dos Direitos Humanos é oriundo da legitimidade de que a igualdade só pode se efetivar pela garantia do direito à diferença. Nesse sentido, respaldando a discussão proposta, Santos e Nunes (2003, p. 56) afirmam que:

Temos o direito a ser iguais quando a nossa diferença nos inferioriza; e temos o direito a ser diferentes quando a nossa igualdade nos descaracteriza. Daí a necessidade de uma igualdade que reconheça as diferenças e de uma diferença que não produza, alimente ou reproduza as desigualdades.

Pensar nessas discussões no âmbito educacional é refletir sobre o multiculturalismo, nos quais os princípios norteadores resultam das incessantes lutas dos marginalizados pelo direito à cidadania, ou seja, o multiculturalismo advém das reivindicações e vivências dos sujeitos que sentiram na pele o triste sabor do preconceito e da discriminação no bojo das sociedades das quais fazem parte. 
Entretanto, como nessa arena multiculturalista mesclam-se sujeitos políticos oriundos de diversas esferas ideológicas, de diferentes grupos e organizações, pesquisadores filiados a diferentes programas de ensino superior, não podemos pensar que há consenso ao tratarmos da questão.

Nessa pesquisa, somos guiados pelas referências do multiculturalismo crítico apresentado por McLaren (1997, 2000), que defende a luta por uma sociedade mais justa e equânime e a convivência entre os diferentes através do diálogo entre as culturas coadunando também com a interculturalidade crítica apresentada por Candau (2005; 2011; 2012) e por Catherine Walsh (2009b), que afirma que ela só faz realmente sentido se estiver situada num contexto de mudança que "esteja assumida de forma crítica, como ação, projeto, processo que procura intervir na refundação das estruturas e ordenação da sociedade que racializa, inferioriza e deshumaniza" (WALSH, 2009b, p. 2).

Consequentemente, temos que organizar na formação inicial e continuada de professores uma dinâmica contínua organizada a partir de uma perspectiva crítica e reflexiva, onde esses sujeitos se enxerguem e enxerguem também os alunos como produtos da cultura, envolvidos nas teias que caracterizam as relações da contemporaneidade. Isso significa abraçar a diferença como um elemento educativo. $\mathrm{O}$ significativo, contudo, não é só valorizarmos as características da diversidade, mas também nos importa como elas foram transformadas em desigualdades, ou seja, como elas foram e são usadas para perpetuar as desigualdades.

Assim, pactuamos com Arroyo (2012), com o fato de que os profissionais da educação vêm se constituindo como “outros". Suas identidades profissionais estão sendo redefinidas, bem como, as pessoais. A identificação dos docentes com os movimentos sociais desencadeia novos olhares para as questões humanas, sociais, culturais e pedagógicas, que incidem sobre a forma de ser educador/a e de visibilizar os estudantes e sobre o conhecimento e as formas de ensinar e aprender. Arroyo (2012) reconhece que os estudantes são sujeitos de direitos, o que imediatamente incide sobre a identidade docente, incorporando novas dimensões. Por isso, se trabalhamos inseridos em um campo social que é reconhecido como um campo de direitos, que é o campo da educação, se, trabalhamos com sujeitos e tempos de direitos, logo, somos profissionais de direitos. 
De acordo com Gomes e Silva (2011) essa perspectiva lança grandes desafios à formação docente porque exigirá a criação de competências que habilitem os professores para compreender, bem como, dominar os processos de construção e apreensão dos saberes sociais e culturais. Exige também, que os processos formativos desenvolvam uma competência que articule teoria e prática onde seja possível acompanhar os diferentes tempos e formas de aprender dos sujeitos socioculturais. "Faz-se necessário formar professores e professoras que saibam lidar pedagogicamente com a diversidade" (GOMES; SILVA, 2011, p. 22), para que os mesmos possam nas escolas, desde a Educação Infantil, vivenciar práticas pedagógicas de emancipação e solidariedade, nas quais as políticas para a infância encarnem a viabilidade de oportunizar que as garantias legais possam se efetivar como direitos, garantindo o acesso às práticas de cidadania, de respeito à cultura e ao conhecimento, pois tal acesso articula-se intimamente com a circulação do poder.

Logo, os espaços educativos como um todo e, particularmente, a Educação Infantil precisam constituir-se como territórios qualificados onde são incorporados a Educação em/para os Direitos Humanos, bem como os desejos e valores de uma sociedade verdadeiramente justa e igualitária. Neste sentido, precisam assegurar uma prática intencional e planejada para a valorização das diferenças e superação das desigualdades.

Guiados por essas premissas, nos perguntávamos: quais práticas pedagógicas estão sendo desenvolvidas pelas professoras da Educação Infantil da microrregião de Garanhuns? Elas buscam a valorização das diferenças ou visam à manutenção das desigualdades? Garanhuns é um dos municípios pernambucanos, situado na Mesorregião do Agreste Meridional formando umas das microrregiões pernambucanas que atende as demandas dos dezenove municípios que ficam no seu entorno. Assim, esta pesquisa teve como objetivo geral: analisar como a questão da diferença é tratada nas práticas pedagógicas de escolas de Educação Infantil da microrregião de Garanhuns. E como objetivos específicos: caracterizar as práticas desenvolvidas na Educação Infantil pelos/as professores/as das redes públicas no que tange a questão do respeito e valorização das diferenças; identificar os elementos que orientam a prática pedagógica na organização da rotina tendo em vista o espaço e tempo na questão da diferença; e, analisar as práticas desenvolvidas a partir da ótica da Educação em/para os Direitos Humanos. Para tal, recorremos aos pressupostos da pesquisa qualitativa de cunho etnográfico observando oito escolas municipais de Educação Infantil em oito 
municípios da microrregião de Garanhuns.

Defendemos que nossas práticas comprometidas com a Educação em/para os Direitos Humanos precisam legitimar e estimar cada um dos/as estudantes presentes na escola, trabalhando na construção e vivência de metodologias que visem ao rompimento do silenciamento, ocultação, invisibilidade e inferiorização de determinados grupos sociais, a partir de práticas críticas e questionadoras dos princípios colonizadores existentes. Práticas essas que não se estruturam apenas pela valorização das características da diversidade, mas na reflexão de como as diferenças foram e são usadas para perpetuar as desigualdades e na luta para que essas desigualdades não se perpetuem como tal. Assim, a interculturalidade que almejamos é "em última instância, um sonho, mas um sonho que se sonha na insônia da práxis" (WALSH, 2009a, p. 28).

\section{Educação em/para os direitos humanos: uma alternativa para visibilizar as diferenças e reduzir as desigualdades desde a educação infantil}

Ao tratarmos da Educação em/para os Direitos Humanos, destacamos como Candau (2007) que ela baseia-se em três pilares: a formação dos sujeitos de direito, o empoderamento e a educação para o nunca mais. O primeiro pilar diz respeito à percepção dos direitos enquanto cidadão. Direitos estes que não são uma dádiva, mas são assegurados por lei. O segundo pilar, diz respeito ao empoderamento do sujeito ou grupos sociais que são tratados como minorias. Este empoderamento é relacionado ao ato de tomada consciência e participação ativa nas ações sociais que compõem a ordem social. É de fato se afirmar cidadão e tomar seu lugar de direito. E o educar para nunca mais se trata do reconhecimento e valorização de cada indivíduo da sua história e a sua cultura, rompendo com a histórica cultura do silenciamento e impunidade.

Dessa forma, destacamos a possibilidade da Educação em/para os Direitos Humanos como uma ferramenta essencial para repensarmos práticas educativas comprometidas com a diferença. Nesse sentido, Dias e Porto (2010) reiteram que a Educação em Direitos Humanos - EDH não abrange apenas as técnicas, processos e métodos de ensinar como as pessoas podem lidar com a questão da diversidade, entretanto, incorpora o respeito à diversidade problematizando-o e redirecionando-o para seu objetivo real que visa à redução e eliminação de todas as formas de discriminação e violência. Assim, defendem que o currículo da EDH na formação inicial, continuada e na Educação Básica seja orientado pelas dimensões da 
intertransdisciplinaridade e da transversalidade, pois essas dimensões representam um pressuposto teórico eficiente para garantir a promoção de uma cultura de direitos, uma vez que elas unem o conhecimento que por questões disciplinares apresenta-se fragmentado, tratando com amplitude e pluralismo as questões que emergem da EDH. Nesse contexto, cabe elucidar que entendemos Educação em Direitos Humanos como:

Um processo sistemático e multidimensional que orienta a formação do sujeito de direitos, articulando as seguintes dimensões: a) apreensão de conhecimentos historicamente construídos sobre direitos humanos e a sua relação com os contextos internacional, nacional e local; b) afirmação de valores, atitudes e práticas sociais que expressem a cultura dos direitos humanos em todos os espaços da sociedade; c) formação de uma consciência cidadã capaz de se fazer presente em níveis cognitivo, social, ético e político; d) desenvolvimento de processos metodológicos participativos e de construção coletiva, utilizando linguagens e materiais didáticos contextualizados; e) fortalecimento de práticas individuais e sociais que gerem ações e instrumentos em favor da promoção, da proteção e da defesa dos direitos humanos, bem como da reparação das violações (BRASIL, 2006, p. 25).

Assim, "o sentido último da Educação em Direitos Humanos é a formação do sujeito de direito que têm como aspiração acabar com as estruturas de injustiças e de discriminação social” (BRASIL, 2013, p. 37). De acordo com Ugarte e Naval (2003), ela é uma educação no sentido pleno, pois favorece o nosso desenvolvimento pessoal, sendo um meio idôneo para a afirmação da dignidade humana.

Como sabemos a história da humanidade é marcada pela intolerância à diferença. Assim, como Garcia (1995), entendemos que um dos grandes desafios que se colocam para a humanidade, na atualidade, é construir uma sociedade em que o diferente não seja considerado "bárbaro, mas seja respeitado em sua diferença, e possa participar da construção coletiva de uma sociedade multicultural”. Como evidenciamos, o respeito do outro como verdadeiramente outro se constitui como uma conquista ainda não consolidada, mas tal questão ultrapassa a simples aceitação ou tolerância. De acordo com Hopenhayn (2011, p. 261), já "não é só a tolerância do outro-distinto o que está em jogo, mas a opção da autorrecriação própria na interação com esse outro". Duschatzky e Skliar (2011, p. 121) afirmam que a alteridade pode ser pensada a partir de três prismas: "o outro como fonte de todo o mal", "o outro como sujeito pleno de um grupo cultural", "o outro como alguém a tolerar".

Nesse cenário, surge a emergência da descolonização dos nossos olhares, saberes e fazeres e o fortalecimento da Educação em/para os Direitos Humanos que 
pode se constituir em um dos caminhos para a mudança, pois abarca a possibilidade de revisitarmos a nossa história, as outras histórias a partir de novas perspectivas, da escuta que efetivamente ouve, do diálogo que não fala em nome de, mas fala com, de relações conjuntas e não fragmentadas, que rompem com a lógica binarista "eu e os outros", nos propondo um "eu como parte dos outros", um eu como parte do mundo, pois a cultura escolar das nossas escolas, desde a Educação Infantil, ainda é construída:

\begin{abstract}
A partir da matriz político-social e epistemológica da modernidade, priorizando o comum, o uniforme, o homogêneo, considerados como elementos constitutivos do universal. Nesta ótica, as diferenças são ignoradas ou consideradas um 'problema' a resolver (CANDAU, 2011, p. 241).
\end{abstract}

Nesse sentido, coadunamos com o argumento de que é preciso e urgente assumir a diferença como um elemento constituinte do processo educativo, tendo em vista que esses são construtos das relações socioculturais. Assim, salientamos que "nenhuma criança que possui a marca da diferença pede tolerância, não há nada a tolerar. Há que tornar a diferença uma positividade, uma afirmação" (ABRAMOWICZ, 2011, p. 37). Todavia, não se trata de pensar a alteridade como amor ao próximo, tampouco a partir dos ideais universais, nem sob a premissa da tolerância com a diversidade cultural, mas de pensarmos além da lógica "nós X outros", reconhecendo a nós mesmos como produto da diferença, ou seja, reconhecendo-nos na outridade do outro, vendo o outro como alguém que vive em mim. "Não se trata aqui de produzir palavras de ordem, sem nenhum significado, mas sim, de pensar sobre o direito da diferença" (ABRAMOWICZ, 2011, p. 37).

De acordo com Arroyo (2012), "o outro" foi produzido como o inexistente. Quando consideramos os outros como marginais, excluídos, desiguais, criamos possibilidades de existência para o nós e os outros. Logo, por não existirem, não há a necessidade de incluí-los, regulá-los, emancipá-los, pois são irrelevantes e incompreensíveis. A impossibilidade de sua copresença tem se configurado como uma maneira eficaz de organizar o sistema brasileiro nos campos político, social, cultural e da educação.

No Brasil, embora o processo de colonização tenha se encerrado, a colonialidade ainda se faz presente entre nós. De acordo com Mignolo (2005), a colonialidade representa o outro lado da Modernidade, o lado não revelado, o lado escuro. Pois a colonização "[...] só concebe o sistema do mundo moderno do ponto de vista de seu 
próprio imaginário, mas não do ponto de vista do imaginário conflitivo que surge com e da diferença colonial" (MIGNOLO, 2005, p. 34). Tal realidade evidencia os efeitos da colonização na nossa forma ainda hoje de olhar para o outro, ou seja, para aquele que não foi incorporado nesse projeto como o superior, o branco, o europeu, o cristão, o heterossexual...

De acordo com Quijano (2005), a colonização influenciou a produção de um novo padrão mundial, produzindo também uma nova intersubjetividade. Para tal feito, a Europa atuou tanto controlando todas as formas de regulação da nossa subjetividade, da cultura e de maneira mais incisiva do conhecimento, quanto da sua produção, reprimindo a forma de produção do conhecimento dos colonizados, suas referências para a produção de sentidos, seu universo simbólico e suas formas de expressão e objetivação da subjetividade, e, ainda, obrigando os colonizados a aprenderem parcialmente sua cultura para utilizá-la nas esferas material, tecnológica e subjetiva, principalmente religiosa.

Arroyo (2012) defende que a forma pedagógica de lidarmos com esses "outros" é valorizando suas formas de resistência à segregação, buscando compreender quais os sentidos políticos dessas presenças afirmativas. $\mathrm{Na}$ medida em que esses setores populares repolitizam os seus lugares na sociedade, que a princípio configuravam-se como inferiorizantes, eles reeducam a sociedade, o Estado e as políticas. Eles também reeducam, anos, professores/as. Eles exigem do campo educacional, de suas teorias, do currículo e da cultura escolar, novas possibilidades de representações. "Exigem ser reconhecidos presentes, resistentes nas fronteiras mais tensas desde o grito colonizador 'terra à vista" (ARROYO, 2012, p. 134).

O primeiro ponto para essa empreitada de repensar a escola pode ser a desconstrução desse imaginário negativo do outro. Assim, devemos reconhecer a presença dos mais diversos coletivos na história da nossa formação social, política, cultural e educacional não apenas como os explorados, marginais sub-humanos, não como "uma história que vem do alto, dos Nós do alto para os Outros de baixo: povão, negros, favelados, quilombolas, indígenas" (ARROYO, 2012, p. 130), mas como seres de luta, resistência e reinvenção. Ao mostrarem-se como sujeitos históricos, essas populações à margem do processo histórico provocam o campo do debate epistemológico e político-pedagógico refutando a sua inexistência.

Logo, para entrar em sintonia com esse tempo, faz-se necessário que os/as educadores/as reconheçam as diferenças e a suas transformações em desigualdades, 
compreendendo os processos históricos, sociais, culturais, políticos e econômicos que as geraram, além de serem capazes de propor ações que se posicionem e que incidam contra toda e qualquer forma de discriminação, ou seja, precisamos implementar uma educação multicultural no cotidiano das escolas. Entretanto, não pode ser qualquer prática multicultural.

Nesse contexto, reconhecemos a perspectiva intercultural assentada na visão crítica que assume a luta por uma sociedade mais justa e equânime, vivificando a convivência entre os diferentes e valorizando o diálogo entre as culturas, proporcionando, dessa maneira, uma abordagem do reconhecimento do outro, orientada pelo panorama de uma sociedade democrática, plural, humana, onde se articulam políticas de igualdade com políticas de identidade, buscando cotidianamente estratégias para enfrentar as inúmeras desigualdades presentes no cotidiano escolar.

\section{Quando a diferença se torna desigualdade: análises e discussões dos dados}

Iniciamos a observação nas escolas registrando as práticas pedagógicas em torno da Lei $n^{\circ} 10.639 / 03$ que foi complementada e substituída pela Lei ${ }^{\circ}$ 11.645/08 que tornou obrigatório o estudo da história e cultura afro-brasileira e indígena, resgatando historicamente a contribuição dos negros e dos indígenas na construção e formação da sociedade brasileira. Dessa forma, a Lei no $11.645 / 09$ possibilita que a criança e negra, e a criança e indígena sejam visibilizadas, respeitadas e tenham a suas diferenças incluídas na Educação Básica. Digo isso, porque o que as pesquisam vêm evidenciando trata-se de um grande descaso com essas populações. Entretanto, a nossa observação, nesta pesquisa, girou em torno da criança e negra.

Embora reconheçamos como Gomes (2006, p. 33), que "não podemos acreditar numa relação causa e efeito entre o preceito legal e a realidade social e educacional", sabemos que as referidas leis representam um grande avanço, mas é no seu embate político, no contexto das relações de poder, na rotina das escolas e na organização e vivências das práticas educativas que elas vão sendo concretizadas.

Ao analisarmos os artefatos culturais que estavam presentes nas escolas, através dos materiais gráficos de comunicação e da decoração, observamos que nas imagens povoam, predominantemente, as representações de crianças brancas, louras com olhos claros. Em todas as escolas observadas haviam apenas dois cartazes com crianças e negras. Assim, a representação da criança e negra acaba por ser uma exceção. A partir 
dessa composição, as crianças e negras que tem esse modelo hegemônico como referencial começam a inferir que existe um padrão de referência e que ela não compõe esse padrão. Essas são estratégias que contribuem para que a criança e negra reconheça que vive numa sociedade marcada pelas diferenças e a diferença que traz no seu corpo, a sua cor, marca a desigualdade de tratamento. As crianças e negras não se veem nesses espaços, buscando então, a representação de quem os ocupa. Ela não é o astro da TV, não é a queridinha da escola, a princesa da professora. Essa representação pode ser compreendida a partir do que nos apresenta Santos (2003, p.27) quando diz que "a história narrada nas escolas é branca, a inteligência e a beleza mostradas pela mídia também o são".

FIGURA 1: Cartazes encontrados na escola
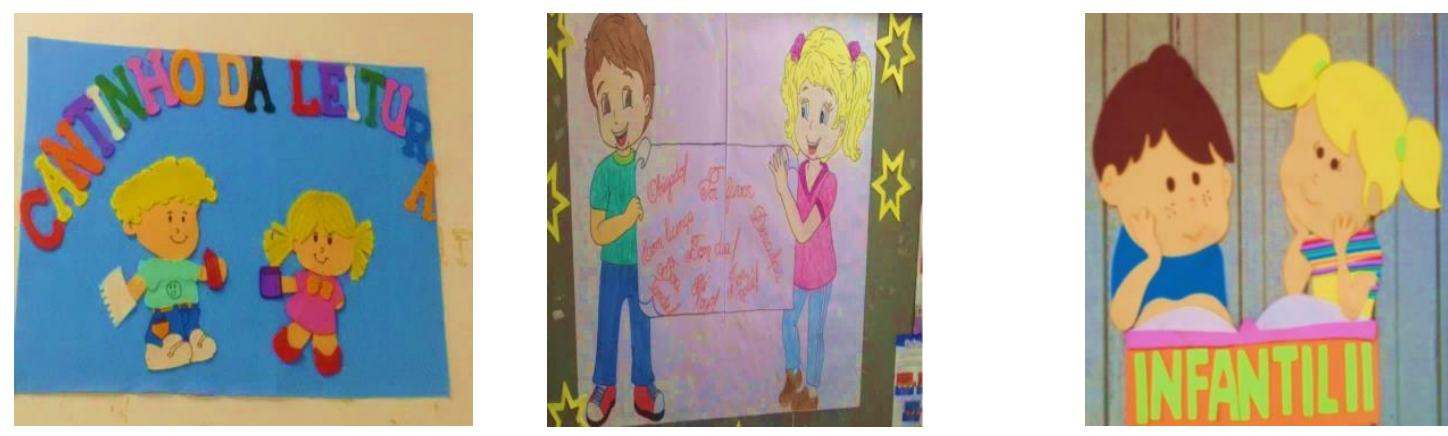

Fonte: Dados da pesquisa (2016).

De acordo com Abramowicz e Oliveira (2006, p. 59) nós necessitamos repensar essa supremacia do modelo hegemônico de vida e de existência, nos perguntando a que perspectiva esse modelo corresponde, bem como, quais os interesses que ele representa, para a partir daí construirmos possibilidades de sobreviver a esse modelo a partir do qual fomos educados e estamos adaptados. Nesse contexto, precisamos desde a formação inicial promover condições para que os/as educadores/as reflitam sobre essas questões.

A disparidade da quantidade entre os materiais que representam a população branca e negra é gritante. Em poucas escolas encontramos bonecos/as negros/as. E nas vezes que encontramos fantoches, bonecos/as, eles estavam guardados nos armários, ou sendo pouco usados pelas professoras, ou ainda extremamente maltratados. Na realidade, a diferença assume um lugar de apêndice, ou seja, não assume a centralidade do processo educativo. Está presente apenas para constar e não de forma equânime. Observa-se, assim que a quantidade está longe de ser paritária. 
FIGURA 2: Boneca negra encontrada na escola

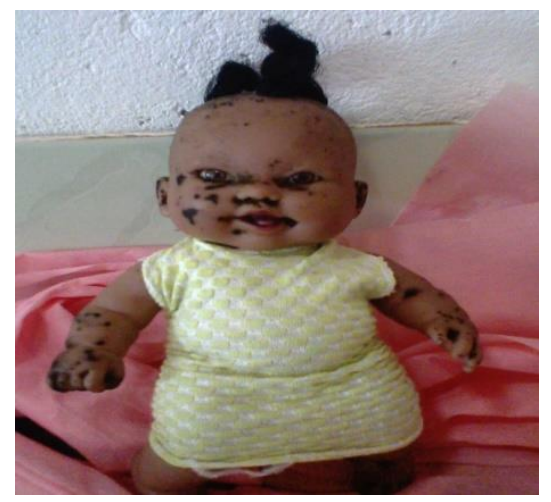

Fonte: Dados da pesquisa (2016).

Reconhecemos que o mercado oferece poucas referências de materiais que contemplem a diferença e que eles são mais caros. Entretanto, encetamos que é papel da escola, junto com seus educadores, criar estratégias para que esse contexto se organize no espaço escolar. Dessa forma, a escola pode se comprometer com a produção de materiais pedagógicos que contemplam a temática através de variadas estratégias. Assim como Moruzzi e Abramowicz (2015, p. 213) "acreditamos que devam se concretizar as propostas de educação das relações étnico-raciais, de modo que as diferenças sejam o coração da proposta educativa das crianças, sem hierarquias nem centro".

Ao buscarmos os livros de literatura infantil, que tem se constituído como uma importante ferramenta para a incorporação da diferença no âmbito escolar, evidenciamos em uma das escolas, um aumento apreciável de livros de literatura infantil relacionados com as questões étnico-raciais. Ao indagarmos uma das professoras da referida escola sobre a utilização desse acervo ela informou que não gosta de trabalhar com esses livros, pois acha os personagens feios.

Frente a essa realidade, entendemos que a presença do material não se constitui como garantia de que ele será utilizado, tampouco que seu uso favorecerá a construção da identidade racial das crianças, e nem que através deles haverá uma ressignificação pedagógica. É partir dessa fala da professora que precisamos refletir sobre a formação dos pedagogos. Para dar conta dessa sociedade justa, equânime, igualitária, pensado no contexto da dimensão das relações étnico-raciais, será necessário incorporar no currículo da formação inicial e continuada dos pedagogos, a discussão sobre a história 
da população negra na diáspora, o mito da democracia racial, a manutenção da hegemonia branca e as lutas contra-hegemônicas.

Moreira (2013) destaca que no debate sobre a formação de professores reforçase o argumento que a organização do currículo para a formação inicial seja norteada a partir das categorias: cultura, conhecimento, poder, ideologia, linguagem e história, preparando os futuros pedagogos para articular a bagagem cultural dos estudantes ao conhecimento escolar visando à formação de uma sociedade que considera a pluralidade etnocultural.

A inserção da discussão das relações étnico-raciais na Educação Infantil exige metodologias que ajudem as crianças a refletirem sobre a branquidade e o eurocentrismo (McLAREN, 1997, 2000), sem termos a ilusão de que responderão positivamente à essa afronta. “[...] É preciso ouvir o que os/as alunos (as) têm vivido, visto e ouvido sobre isso" (BARREIROS, 2005, p. 111). Logo, é também necessário ter professores/as preparados para essa vivência.

No que se refere à promoção da diversidade religiosa na Educação Infantil salientamos a necessidade de perceber as inúmeras cegueiras que permeiam o diálogo inter-religioso que se consolidam a partir das constantes ações de negação, desqualificação, sobreposição, desvalorização e exclusão dessa discussão na escola, expondo os efeitos da colonização cosmogônica (WALSH, 2009b) no cotidiano escolar.

Os dados coletados evidenciam que, desrespeitando a importância da liberdade religiosa, as crianças de 0 a 5 anos na microrregião de Garanhuns têm sido comumente expostas às convicções de uma determinada confessionalidade, perdendo a oportunidade de na escola construir conhecimentos sobre a diversidade cultural religiosa brasileira e vivenciar práticas de respeito ao outro. Ao percorremos as escolas pudemos encontramos uma série de imagens espalhadas que anunciam como a questão da diversidade religiosa é tratada.

FIGURA 3 Imagens religiosas presentes nos cartazes e murais das escolas
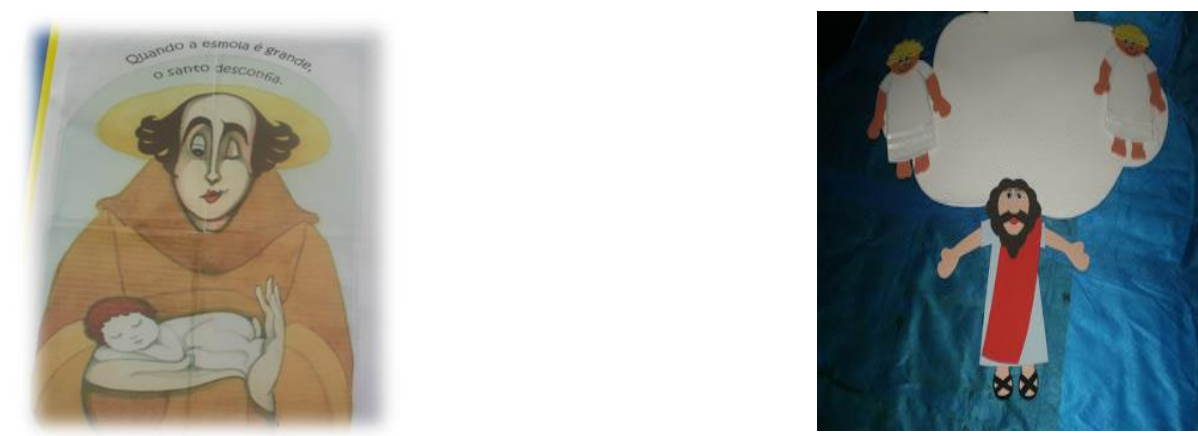

Fonte: Dados da pesquisa (2016) 
Em uma das escolas foi observado que as crianças rezam quatro vezes ao dia: na entrada, antes e depois do lanche e na saída. Em outra escola, formam-se rodas no pátio e cada turma reza uma Ave-Maria. Na escola existem seis turmas e na entrada são rezadas seis Ave-Marias. Ou ainda, a disposição das crianças num espaço externo à escola para que uma vez por mês cantem as músicas de um determinado padre independentemente da religião das crianças. A gestora dessa escola ao ser questionada sobre a presença de crianças que não pertencem a religião católica nessas atividades, respondeu que não sabia e que não havia nenhum problema que as crianças rezassem o pai-nosso e a oração do santo-anjo.

Acompanhamos ainda o momento da contação de histórias. Presenciamos a contação de vários contos bíblicos acompanhados de processos de doutrinação religiosa. No Brasil, é a partir de 1997 com a Lei no 9.475 que se iniciou a proposição do Ensino Religioso como uma forma de acesso aos conhecimentos religiosos como um dos patrimônios da humanidade e não como uma forma de doutrinação religiosa. Em uma das contações observadas sobre a história de Adão e Eva e o surgimento do pecado, a professora relaciona o pecado à sujeira e chama um aluno para fazer a representação. Ela enfatiza que ao pecarmos ficamos com o coração sujo, impuro e pede para o aluno pintar o coração que está desenhado numa folha de ofício colada no quadro com a tinta preta, associando o pecado às impurezas.

De acordo Fórum Nacional Permanente de Ensino Religioso (FONAPER, 2009) o ensino religioso, deve partir primordialmente, das experiências dos alunos, tomando como referência o contexto sociocultural de cada estudante. Nesse cenário, a prática docente pode ser fundamentada pelos valores da diversidade cultural religiosa, possibilitando o direito à afirmação das diferenças e promovendo uma Educação em/para os Direitos Humanos. A escola, enquanto lugar privilegiado de convívio entre as diferentes culturas, não pode ser organizado como lugar de homogeneização religiosa. Entretanto, as práticas que presenciamos nas turmas de Educação Infantil negam o direito às crianças de vivenciarem a escola como um espaço de garantia à liberdade religiosa, onde através da igualdade de acesso ao conhecimento de todas as culturas, tradições/grupos religiosos e não religiosos elas podem dialogar com as diferenças. 
FIGURA 4: Contação de histórias
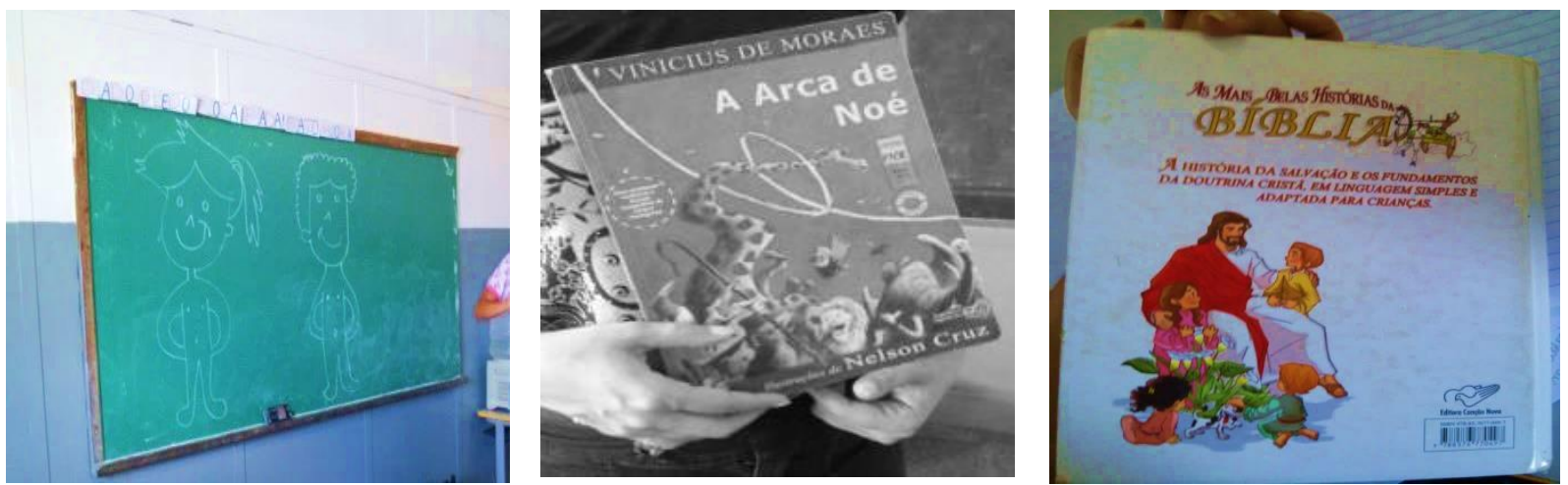

Fonte: Dados da Pesquisa (2016)

Assim, torna-se necessário possibilitar tempos e espaços desde os primeiros momentos da criança na escola para a vivência da diversidade cultural religiosa, interrompendo as relações de poder que assumem uma perspectiva proselitista que impossibilita a representação de diversas formas religiosas na escola. Nesse contexto, torna-se urgente repensar e reinventar práticas pedagógicas que de acordo com Cecchetti, et al. (2013) possibilitem o exercício da sensibilidade diante de qualquer forma de discriminação religiosa, notabilizando as cegueiras que produzem injustiça, bem como, processos de exclusões e desigualdades.

Ao observarmos a questão da identidade de gênero, reconhecendo-a como uma construção social, o que se constatou nas escolas observadas foi um reforço dos "scripts de gênero" (ZANETTE; FELIPE, 2017), ou seja, as práticas pedagógicas propostas na escola contribuem para a construção do lugar do que culturalmente é definido como masculino e feminino, "produzindo assim diferenças que se desencadeiam na constituição corporal, nas expectativas que temos em torno desse corpo e como vemos" (ZANETTE; FELIPE, 2017, p. 21). Louro (1997) afirma que as relações sociais são atravessadas por diferentes discursos, símbolos, representações e práticas. É dessa forma que os sujeitos vão se construindo como masculinos ou femininos, arranjando e desarranjando seus lugares sociais, suas disposições, suas formas de estarem no mundo. “Assim, gênero tem sido cada vez mais usado para referir-se a toda construção social relacionada à distinção e hierarquia masculino/feminino, incluindo também aquelas construções que separam os corpos em machos e fêmeas, mas indo muito além disso" (CARVALHO, 2013, p. 92). Conforme afirma Joan Scott (1995), o gênero pode ser compreendido como a organização social da diferença sexual. A autora classifica gênero como sendo um elemento que constitui as relações sociais. Em uma dada cultura 
homens e mulheres a partir de interações sociais se constroem gradativamente e estabelecem posturas distintas que são relativas ao gênero a que pertence.

As relações de gênero e poder nos processos de socialização de crianças pequenas são repletas de estratégias voltadas à normalização e ao controle das expressões corporais. Formas de controle disciplinar estão intrinsecamente relacionadas à demarcação das fronteiras entre feminino e masculino, bem como ao reforço de características físicas e comportamentos esperados para cada sexo nos pequenos gestos ou nas práticas rotineiras da educação infantil (FINCO, 2013, p. 06).

Dessa forma, os meninos são incentivados a brincarem na escola geralmente das brincadeiras mais agitadas, (futebol, luta), porque são tidos como fortes, ágeis, enquanto as meninas são incentivadas a brincarem de forma mais "calma" (boneca, casinhas, jogos), porque são mais dóceis e meigas. As próprias crianças distinguem o que são as brincadeiras de meninos e de meninas. Essas constatações evidenciaram que, para as crianças, o gênero limita e marca o que deve ou não se fazer a depender do sexo a que elas pertencem. De forma mais latente, observou-se o fortalecimento do uso de cores diferentes para meninos e meninas, bem como, de objetos diferentes.

Em uma das escolas as crianças receberam da professora uma atividade de colorir, como era época das festas juninas, na atividade havia um menino e uma menina com vestimentas típicas. As crianças podiam colorir ao seu modo. Mas, logo escutamos uma menina dizendo pra um menino: “- Pinta o vestido dela de rosa." e o menino pinta de rosa como foi proposto. Mas, ele também pinta a roupa do menino da imagem de rosa e a menina diz: "-Ui bichinho, você errou... o menino não é de rosa”. O menino tenta consertar e pinta imediatamente a roupa do boneco da imagem de azul.

As crianças possuem de maneira bem evidente nas suas falas e ações, marcadores de identidade de gênero. Elas se reconhecem e se identificam a partir das cores, para as crianças a cor rosa é uma identificação para o sexo feminino, já a cor azul para o sexo masculino. As cores rosa e azul funcionam para as crianças como uma bússola, algo que é tido como conhecimento, descoberta e identificação "sou menina, meu mundo é rosa", "sou menino, meu mundo é azul".

Ao considerarmos o contexto da Educação Inclusiva, reconhecemos que o Brasil formalizou o seu engajamento na luta através da adesão à vários acordos internacionais, admitindo a sua escolha política em favor da universalização do ensino que assegure para todos/as acesso ao conhecimento, bem como, as condições necessárias para o 
ensino-aprendizagem. Assim, ao observarmos as escolas de Educação Infantil priorizamos a questão das adaptações curriculares, ou seja, almejávamos observar como o currículo proposto estava sendo modificado para atender as necessidades dos educandos. Buscávamos as alterações que visassem à reorganização do que o aluno deveria aprender, como e quando aprender, e as formas propostas para assegurar a aprendizagem e a avaliação do estudante com necessidades especiais.

Nesse sentido, ao observarmos a questão da Educação Inclusiva inferimos que o entendimento por parte das escolas do processo inclusivo é basicamente perpassado pela ideia de tornar a escola "acessível". Assim, visibilizamos na maioria das escolas a construção de rampas nas entradas das escolas e alguns banheiros adaptados. Mas, no que se refere à prática pedagógica do professor na sala de aula, não observamos a utilização de estratégias metodológicas diversificadas que favorecem o manejo da forma como os conteúdos são propostos, adequando-os aos variados tipos de aprendizagem de cada estudante, embora haja redes municipais em que as crianças contam com estagiários para o apoio pedagógico; nem práticas que proporcionavam a utilização de estratégias de aprendizagem cooperativa, pois, como já sabemos, os estudantes aprendem também com seus pares; nem a oferta de experiências e atividades diversificadas que permitam propor o trabalho com determinados conteúdos que possuem diversos graus de complexidade e, inclusive, conteúdos distintos que podem ser vivenciados de formas diferentes; tampouco o fomento contínuo de momentos para que os alunos pratiquem de forma autônoma e independente o que aprenderam, o que presenciamos foi um reforço da dependência dos estudantes com necessidades especiais dos estagiários que os acompanham; a organização dos estudantes de acordo com diferentes critérios utilizando diferentes tipos de agrupamento de alunos de acordo com a atividade proposta, de forma a favorecer a construção de diferentes aprendizagens de acordo com o objetivo estabelecido, com o conteúdo proposto e com as peculiaridades e interesses dos estudantes; a disposição do espaço da sala de aula organizada de maneira que se torne agradável para o professor e para o estudante, facilitando a autonomia e a mobilidade dos alunos, em geral, as crianças com necessidades especiais ficam isoladas no restante da sala ocupando lugares no fundo da sala; e por fim, não se observou o fomento de um clima de respeito e de valorização das diferenças entre os pares, ajudando as crianças a valorizarem a diferença. 


\section{Por uma escola que celebra as diferenças: considerações finais}

As escolas que têm na sua centralidade a compreensão da diferença têm ofertado elementos para que os estudantes, desde a Educação Infantil, construam sua identidade positivamente, bem como para a composição de uma sociedade democrática, plural e humana. Coerente com essa situação, Abramowicz e Levcovitz (2010) destacam que a diferença precisa ser retirada desse lugar do estranho, do horrível, da aberração, da cena em que foi satanizada para que a criança possa construir novas possibilidades de agenciamentos, afetos e amizades. Dias (2012) reforça esse argumento, salientando que é preciso considerar as diferenças entre as pessoas como valor positivo, exacerbando que é importante nos posicionarmos contra políticas de identidades que estabelecem hierarquias entre as pessoas, onde a diferença se torna algo negativo.

Ao evidenciarmos esse diagnóstico nas escolas observadas, propusemos posteriormente intervenções mediadas pelos estudantes do curso de Pedagogia, da Especialização Lato Sensu em Gestão Escolar e Coordenação Pedagógica e em Psicopedagogia por reconhecermos que precisamos como agentes socioculturais e políticos que somos, contribuir para a construção de uma sociedade mais justa e plural que reconhece, acolhe e celebra as diferenças e luta pela redução das desigualdades. Entretanto, sabemos que a luta descolonizadora, pela construção da interculturalidade na perspectiva crítica é um processo em movimento contínuo e em um momento inicial de construção. Todavia, precisamos como educadores/as comprometidos/as com uma nova humanidade termos a compreensão de que a nossa sociedade ainda vive sob a égide de um processo de colonialidade. Mas a infância não para, não espera. Assim, as práticas no sentido da descolonização do poder, do saber, do ser e cosmogônica precisam ser constantes, intensas. Exigem uma urgência para que as desigualdades não se cristalizem e assumam mais fortemente o contexto da normalidade.

Assim, ao evidenciar a realidade na Educação Infantil da microrregião de Garanhuns, reforçamos a importância de fortalecermos a nossa atuação como professores da Formação Inicial dos cursos de licenciatura buscando a construção de estratégias que tragam para o cerne da formação docente e para escola da Educação Básica o direito à diferença desde a Educação Infantil, na compreensão que toda criança não suporta e não merece o preconceito e a discriminação que ainda são vítimas na escola. Assim, essa pesquisa caminhou no sentido de coadunar com uma expressão utilizada pelos zulus, Ubuntu, “eu sou porque nós somos”. Estamos juntos na luta por 
uma sociedade equânime, por mais justiça social e menos desigualdades. Mais humanidade na escola!

\section{REFERÊNCIAS}

ABRAMOWICZ, Anete. A pluralidade de ser judeu. In: GOMES, Nilma Lino; SILVA, Petronilha B. Gonçalves (Org.). Experiências étnico-culturais para a formação de professores. 3. ed. Belo Horizonte: Autêntica, 2011. p. 27-38.

ABRAMOWICZ, Anete; LEVCOVITZ, Diana. Tal infância. Qual criança? In: Afirmando diferenças: montando o quebra-cabeça da diversidade na escola. Campinas, São Paulo: Papirus, 2010, p. 73-86.

ABRAMOWICZ, Anete.; OLIVEIRA, Fabiana. A escola e a construção da identidade na diversidade. In: ABRAMOWICZ, Anete.; BARBOSA, Lucia Maria de Assunção.; SILVÉRIO, Valter Roberto (Orgs.). Educação como prática da diferença. Campinas, SP: Armazém do Ipê, 2006. p. 41-64.

ABREU, Márcia.; CORDIOLLI, Marcos (Orgs.). O projeto de lei do plano nacional de educação (PNE): projeto em tramitação no congresso nacional. Brasília: Câmara dos Deputados; Comissão de Educação e Cultura, 2011. (Cadernos CEC, 1).

ARROYO, Miguel Gonzáles. Outros Sujeitos, outras pedagogias. Petrópolis: Vozes, 2012.

BARREIROS, Cláudia Hernandez. Dialogando com Peter McLaren: em busca de uma prática pedagógica multicultural e crítica. In: CANDAU, V. M. (Org.). Cultura(s) e educação: entre o crítico e o pós-crítico. Rio de Janeiro: DP\&A, 2005, p. 95-114.

BRASIL. Educação em direitos humanos: diretrizes nacionais. Brasília: Coordenação Geral de Educação em SDH/PR, Direitos Humanos, Secretaria Nacional de Promoção e Defesa dos Direitos Humanos, 2013.

BRASIL. Lei $\mathbf{n}^{\mathbf{1}} \mathbf{1 1 . 6 4 5}$ de 10 de março de 2008. Disponível em: <http://www.planalto.gov.br/ccivil_03/_Ato2007-2010/2008/Lei/L11645.htm>. Acesso em: 10 maio 2017.

BRASIL. Plano nacional de educação em direitos humanos. Brasília: Secretaria Especial dos Direitos Humanos, Ministério da Educação, Ministério da Justiça, UNESCO, 2006.

CANDAU, Vera Maria. Multiculturalismo e educação: desafio para a prática pedagógica. In: MOREIRA, Antonio Flávio.; CANDAU, Vera Maria (Orgs.). Multiculturalismo: diferenças culturais e práticas pedagógicas. Petrópolis: Rio de Janeiro: Vozes, 2011. p. 13-17. 
CANDAU, Vera Maria. Educação em direitos humanos: desafios atuais. In: SILVEIRA, Rosa Maria Godoy (Org). Educação em Direitos Humanos: fundamentos teóricometodológicos. João Pessoa: Universitária/UFPB, 2007. p. 399-411.

CARVALHO, Marília Pinto de. Gênero na sala de aula: a questão do desempenho escolar. In: MOREIRA, Antonio Flávio.; CANDAU, Vera Maria. (org.) Multiculturalismo diferenças culturais e práticas pedagógicas. Petrópolis: Vozes, 2013. Cap. 4, p. 90-124.

CECCHETTI, Elcio. et al. Diversidade religiosa e direitos humanos: conhecer, respeitar e conviver. In: FLEURI, Reinaldo Matias et al. (Orgs): Diversidade religiosa e direitos humanos: conhecer, respeitar e conviver. Blumenau: Edifurb, 2013.

DIAS, Adelaide Alves.; PORTO, Rita de Cássia Cavalcanti. A Pedagogia e a Educação em Direitos Humanos: subsídios para a inserção da temática da Educação em Direitos Humanos nos cursos de Pedagogia. In: FERREIRA, Lúcia de Fátima Guerra. et al. Direitos Humanos na Educação Superior: Subsídios para a Educação em Direitos Humanos na Pedagogia. João Pessoa: Editora Universitária da UFPB, 2010, p. 29-70.

DIAS, Lucimar Rosa. Formação de professores, educação infantil e diversidade étnicoracial: saberes e fazeres nesse processo. Revista Brasileira de Educação, v. 17, n. 51, p. 661-749, set./dez. 2012.

DUSCHATZKY, Silvia.; SKILIAR, Carlos. O nome dos outros: narrando a alteridade. In: LARROSA, Jorge; SKILIAR, Carlos. Habitantes de Babel: políticas e poéticas da diferença. 2. ed. Belo Horizonte: Autêntica Editora, 2011, p.119-162.

FINCO, Daniela. Educação infantil, espaços de confrontos e convívio com as diferenças: análise das interações entre professoras e meninas e meninos que transgridem as fronteiras de gênero. 2010. 198 f. Tese (Doutorado em Educação) - Programa de Pós-Graduação em Educação, Universidade de São Paulo, São Paulo, SP, 2010.

GARCIA, Regina Leite. Currículo emancipatório e multiculturalismo: reflexões de viagem. In: SILVA, Tomaz Tadeu da.; MOREIRA, Antônio Flávio (Orgs.). Territórios contestados: o currículo e os novos mapas políticos e culturais. Petrópolis: Vozes, 1995. p. 114-143.

GOMES, Nilma Lino. Diversidade cultural, currículo e questão racial: desafios para a prática pedagógica. In: ABRAMOWICZ, Anete.; BARBOSA, Lúcia Maria de Assunção Barbosa.; SILVÉRIO, Valter Roberto. Educação como prática da diferença. Campinas, SP: Armazém do Ipê, 2006. p. 21-40.

LOURO, Guacira Lopes. Gênero, sexualidade e educação: uma perspectiva pósestruturalista. Rio de Janeiro: Vozes, 1997.

MCLAREN, Peter. Multiculturalismo crítico. São Paulo: Cortez, 1997.

LOURO, Guacira Lopes. Multiculturalismo revolucionário: pedagogia do dissenso para o novo milênio. Porto Alegre: ed. ArtMed, 2000. 
MIGNOLO, Walter. A colonialidade de cabo a rabo: o hemisfério ocidental no horizonte conceitual da modernidade. In: LANDER, Edgardo. A colonialidade do saber: eurocentrismo e ciências sociais - perspectivas latino-americanas. Buenos Aires: CLACSO, 2005.

MORUZZI, Andrea Braga.; ABRAMOWICZ, Anete. Infância, raça e currículo: alguns apontamentos sobre os documentos brasileiros para a educação infantil. Revista Contemporânea de Educação, v. 10, n. 19, p. 199-214, jan./jul. 2015.

QUIJANO, Aníbal. Colonialidade do poder, eurocentrismo e América Latina. In: LANDER, Edgardo (Org.). A colonialidade do saber: eurocentrismo e ciências sociais. Buenos Aires: Conselho Latino-americano de Ciências Sociais - CLACSO, 2005.

SANTOS, Boaventura Santos.; NUNES, João Arriscado. Introdução: para ampliar o cânone do reconhecimento, da diferença e da igualdade. In: SANTOS, Boaventura Santos; (org.). Reconhecer para libertar: os caminhos do cosmopolitismo multicultural. Rio de Janeiro: Civilização Brasileira, 2003, p. 25-68.

SANTOS, Hélio. A busca de um caminho para o Brasil: a trilha do círculo vicioso. São Paulo: SENAC, 2003.

SCOTT, Joan Wallach. Gênero: uma categoria útil de análise histórica. Porto Alegre: Educação \& Realidade, 1995

SILVA, Elisa Rodrigues.; SANTANA, Valdineia. Brasil-África, importância, reconhecimento, ressignificação. Brasília: UNESCO, 2012. (Debates e perspectivas para a institucionalização da Lei $\left.n^{\circ} 10.639 / 2003\right)$.

TEIXEIRA, Faustino. O desafio da mística comparada. In: TEIXEIRA, F. (org.). No limiar do mistério: mística e religião. São Paulo: Paulinas, 2004. p. 13-31. (Religião e Cultura).

UNESCO. Declaração universal sobre a diversidade cultural. UNESCO, 2002. Disponível em: <http://unesdoc.unesco.org/images/0012/001271/127160por.pdf>. Acesso em: 10 ago. 2015.

WALSH, Catherine. Interculturalidade crítica e pedagogia decolonial: in-surgir, reexistir e re-viver. In: CANDAU, Vera Maria (Org.). Educação Intercultural na América Latina: entre concepções, tensões e propostas. Rio de Janeiro: 7 Letras, 2009a. p. 12-42.

WALSH, Catherine. Interculturalidade e (des) colonialidade: perspectivas críticas e políticas. In: CONGRESSO ARIC, 12., 2009, Florianópolis. Anais... Florianópolis: ARIC 2009b.

ZANETTE, Jaime Eduardo.; FELIPE, Jane. Os enigmas da infância: quando a transexualidade tensiona os scripts de gênero. In: ALBUQUERQUE, Simone Santos de.; FELIPE, Jane.; CORSO, Luciana Vellinho. (org.) Para pensar a Educação Infantil em tempos de retrocessos. Porto Alegre: Evangraf, 2017, p. 17-35. 


\section{Como referenciar este artigo}

SILVA, Tarcia Regina. Educação em e para os direitos humanos: a escola e o direito a afirmação da diferença. Revista on line de Política e Gestão Educacional, Araraquara, v.21, n. esp.2, p. 1076-1097, nov. 2017. Disponível em: <http://dx.doi.org/10.22633/rpge.v21.n.esp2.2017.10176>. ISSN: 1519-9029.

Submetido em: 30/07/2017

Aprovado em: 21/09/2017 